\title{
An Ecological Perspective on Nanomaterial Impacts in the Environment
}

\author{
Emily S. Bernhardt* and Benjamin P. Colman Duke University \\ Michael F. Hochella, Jr. Virginia Tech \\ Bradley J. Cardinale and Roger M. Nisbet University of California-Santa Barbara \\ Curtis J. Richardson and Liyan Yin Duke University
}

Growing concerns over the potential for unintended, adverse consequences of engineered nanoparticles (ENPs) in the environment have generated new research initiatives focused on understanding the ecological effects of ENPs. Almost nothing is currently known about the fate and transport of ENPs in environmental waters, soils, and sediments or about the biological impacts of ENPs in natural environments, and the bulk of modern nanotoxicogical research is focused on highly controlled laboratory studies with single species in simple media. In this paper, we provide an ecological perspective on the current state of knowledge regarding the likely environmental impacts of nanomaterials and propose a strategy for making rapid progress in new research in ecological nanoscience.
Copyright $\odot 2010$ by the American Society of Agronomy, Crop Science Society of America, and Soil Science Society of America. All rights reserved. No part of this periodical may be reproduced or transmitted in any form or by any means, electronic or mechanical, including photocopying, recording, or any information storage and retrieval system, without permission in writing from the publisher.

J. Environ. Qual. 39:1954-1965 (2010)

doi:10.2134/jeq2009.0479

Published online 23 Sept. 2010.

Supplemental data file available online for this article.

Received 6 Dec. 2009.

*Corresponding author (ebernhar@duke.edu).

(c) ASA, CSSA, SSSA

5585 Guilford Rd., Madison, WI 53711 USA

\section{Two Contrasting Views of Nanotechnology}

Unconstrained Optimism: When we get to the very, very small world-say circuits of seven atoms-we have a lot of new things that would happen that represent completely new opportunities for design. Atoms on a small scale behave like nothing on a large scale, for they satisfy the laws of quantum mechanics. So, as we go down and fiddle around with the atoms down there, we are working with different laws, and we can expect to do different things. We can manufacture in different ways.

—Richard Feynman (1959), "There's Plenty of Room at the Bottom"

Ungrounded Fear: In the Nevada desert, an experiment has gone horribly wrong. A cloud of nanoparticles-microrobots- has escaped from the laboratory. This cloud is selfsustaining and self-reproducing. It is intelligent and learns from experience. For all practical purposes, it is alive.

-Introduction to Michael Crichton's 2002 novel Prey

IN I959, PHYSICIST AND VISIONARY Richard Feynman called on his colleagues to explore the possibilities of storing libraries of information on cards the size of a pinhead and of creating machines only tens to hundreds of atoms in size. Five decades later, Feynman's visionary ideas are widely credited with stimulating the birth and growth of nanotechnology. Massive amounts of information are stored on ever smaller chips, and the production and diversification of engineered nanomaterials is increasing exponentially. Nanotechnologies are creating a host of newfound capabilities in industry, manufacturing, and medicine-as precise configurations of "atoms on a small scale behave like nothing on a large scale" (Feynman, 1959). These same capabilities are generating increasing concern about what impact these novel materials may have when they enter human bodies and natural ecosystems. In his novel Prey, Michael Crichton (2002) played on these fears in a scientific thriller in which engineered nanoparticles escaped

E.S. Bernhardt, B.P. Colman, and L. Yin, Dep. of Biology, Box 90338, Duke Univ., Durham, NC 27708; M.F. Hochella, Jr., Dep. of Geosciences, 5049 Derring Hall, Virginia Tech, Blacksburg, VA 24061; B.J. Cardinale and R.M. Nisbet, Dep. of Ecology, Evolution and Marine Biology, Building 408, Univ. of California-Santa Barbara, Santa Barbara, CA 93106; C.J. Richardson, Nicholas School of the Environment, Duke Univ., Durham, NC 27708. Assigned to Associate Editor Joel Pedersen.

Abbreviations: CNT, carbon nanotube; DEB, Dynamic Energy Budget; ENP, engineered nanoparticle; QSAR, quantitative structure-activity relationship. 
from a factory, gained the capacity to reproduce, and began to behave collectively as a predatory nanoswarm. The plot is exceedingly farfetched, but the sentiment, that nanomaterials are new and frightening, is increasingly prevalent in the popular press and blogosphere. These nebulous concerns are not slowing the growth of nanotechnology, which currently represents a greater than $\$ 100$ billion dollar global industry, with some analysts predicting that global revenues from nanotechnologyenabled products will be worth $\$ 2$ to 3 trillion by 2015 (estimates from Global Industry Analysts Inc. and Lux Research). More than 1000 products that contain nanomaterials are currently commercially available, with thousands more in development (Project on Emerging Technologies 2009). Scientific discovery about nanomaterials is also increasing exponentially; over the last decade $>100,000$ peer-reviewed papers have been published on the topic of nanomaterials or nanoparticles. Yet our understanding of what nanomaterials do (outside of their original commercial or industrial purposes) to organisms or within natural environments lags far behind our ability to engineer new nanomaterials (engineered nanoparticles [ENPs]).

Fortunately, there are not yet any known instances of ENP spills or ENP pollution in the environment, and thus it is not currently possible to document the ecological impacts of ENPs in the field. At present, we are poorly equipped to answer questions about the potential environmental impacts of ENPs. Studies of the likely environmental consequences of nanoparticle exposures lag far behind reports of nanomaterial fabrication, characterization, and usage. A rapidly growing body of toxicological studies suggest that a number of nanomaterials may be toxic (reviewed by Kahru and Dubourguier, 2009), yet there are currently no regulations that limit nanomaterial exposures (Powell et al., 2008). It is widely recognized that the environmental impacts of nanomaterials need to be understood (an ISI Web of Science [http://apps.isiknowledge.com/; verified 8 Sept. 2010] online search on [nanomaterial* OR nanoparticle ${ }^{*}$ + [environment] + [review] returns $>20$ articles published in the last $3 \mathrm{yr}$ ) and both the USEPA and the European Commission (reviewed in Sass et al., 2008 and in Kahru and Dubourguier, 2009) have called for empirical research and risk assessment to help guide rulemaking. In response, government funding is offering the opportunity to develop a proactive, mechanistic understanding of how ENPs are likely to influence organisms and ecosystem processes before significant exposures. Ideally, this information should contribute to regulatory and market-driven frameworks that will prevent or mitigate for harmful ENP impacts.

While new funding initiatives for ecological research represent a unique opportunity for ecologists to study these emerging technologies, it also presents significant challenges to a field of research that has little history of predicting the impact of contaminants on the environment. Typically, due to a lack of awareness or a lack of funding, ecologists have had the opportunity to study pollutants only after they have already caused significant environmental degradation. We were invited to write a review of ecological effects of engineered nanomaterials, but given the scarcity of ecological research on this topic, such a paper would be both brief and premature. Instead, our goal in this paper is to (i) provide an ecological perspective on what we know so far about the environmental impacts of nanoparticles, and (ii) propose guidelines and strategies for making rapid and strategic progress in gaining an ecological understanding of ENP impacts in the environment.

\section{What Are Nanomaterials and What Do We Know about Their Environmental Impacts?}

One of the underlying problems in determining the environmental impact of nanomaterials is that there is nothing simple about them. In fact, essentially all of their fundamental properties and behaviors are challenging to assess and study, although a great deal of progress in the last decade or two has been achieved. This difficulty arises because nanomaterials can exist in many forms and sizes between the molecular state on the one hand, and the bulk state on the other, keeping in mind that both bounding states have been relatively well understood for a considerable period of time.

Nanomaterials are generally defined as materials that are $<100 \mathrm{~nm}(0.1 \mu \mathrm{m})$ in at least one dimension. This means that nanomaterials can be three-dimensional particles of almost any shape, ultrathin films (two-dimensional-like), or fine rods (essentially one-dimensional). Ecologists have good reason to believe that even this shape difference will play a big role in their environmental, and specifically, their biological influences. But most importantly, and far beyond this simple classification with respect to size, nanomaterials are so fascinating because their properties, and therefore their environmental/biological behavior, depend on their size. This is to say that their chemical (reactivity, solubility, etc.), mechanical (elasticity, hardness, etc.), electronic (conductivity, redox behavior, etc.), and nuclear (magnetic) properties often change as a function of size. These changes can be, and often are, dramatic. This is precisely what leads to their exceptional (some would say astronomical) commercial value, and their anticipated enigmatic behavior in an already extraordinarily complex earth environment. Although the reasons for these changes are varied and often complex, one can simply keep in mind that the underlying cause is generally related to the rapid rise in surface-to-volume ratio as one descends down through this size range, keeping in mind that the atomic (and electronic) structure of the surface region is different from the "bulk" material below. Therefore, in the nanoworld, not only do the properties of a material depend on the chemical composition and atomic structure of that material, as is true for any biotic or abiotic material, but also on its size.

\section{Naturally Occurring Nanoparticles Are Ubiquitous in Nature}

The lack of ecological studies of nanomaterials in a typical literature search is misleading. Ecological research on ENPs can take advantage of the wealth of oceanic, terrestrial, and atmospheric earth science research involving naturally occurring nanoparticles. In particular, there are significant physical and chemical similarities between the most widely manufactured ENPs and naturally occurring nanoparticles, although in a number of cases the exact size, shape, and coatings/surface functional groups may be quite different from ENPs. Also, while the term nanoparticle may not yet be widely used in ecology, earth scientists have been studying at least some major classes of natural nanoparticles for many decades. For example, it was realized years ago that the charged surfaces of clays in soil—an example of natural nanoparticles - were known 
to form electrostatic bonds with ions (e.g., $\mathrm{NH}_{4}^{+}, \mathrm{Ca}^{2+}, \mathrm{K}^{+}$, and $\mathrm{Mg}^{2+}$ ) that contribute substantially to soil fertility by preventing the loss of these vital nutrients to groundwater (Gieseking, 1939; Eriksson, 1952). Now, modern nanoscience has become an integral part of soil science that goes far beyond the study of clay minerals (see reviews and perspectives by Maurice and Hochella, 2008; Theng and Yuan, 2008).

This and other aspects of nanogeoscience, as it is now called, have extensively developed relatively recently, particularly in the last decade (see reviews by Banfield and Navrotsky, 2001; Hochella, 2002; Hochella et al. 2008). This is because an exceptionally wide variety of nanoparticles exist on earth, and are in fact ubiquitous in both the biotic and abiotic compartments of earth (Gilbert and Banfield, 2005; Hochella et al., 2008). The most abundant of these particles include ash from volcanoes and forest fires, sea salt aerosols, and the iron and other transition metal oxides in soils, rivers, and oceans (Hochella, 2008; Buseck and Adachi, 2008; Kulmala and Kerminen, 2008; Hassellöv and von der Kammer, 2008; and references therein). It has also been demonstrated that naturally occurring nanoparticles have important local, regional, and even global consequences. For example, it has been shown that airborne nanoparticles (and larger dust particles) link the deserts of Africa with the productivity of the open ocean and help sustain the nutrient demands of terrestrial ecosystems worldwide (Chadwick et al., 1999; Jickells et al., 2005; Prospero, 1999; Simonson, 1995). We now know that naturally occurring nanoparticles are even present in interplanetary and interstellar space (Hochella, 2008). They have also been abundant on earth since its formation, were part of its formation (Becker et al., 2006), and life from the beginning has evolved in their presence. Emerging research is suggesting that many organisms synthesize nanomaterials. Bacteria in sediments may synthesize electrically conductive pilli, called nanowires, for sensing neighbors or for transferring electrons and energy (Blango and Mulvey, 2009; Gorby et al., 2006). Bacterial reduction of uranyl, $\mathrm{U}^{6+}(\mathrm{aq})$, to $\mathrm{U}(\mathrm{IV})$ oxide (uraninite) is an important bioremediation strategy (Bargar et al., 2008). Manceau et al. (2008) found that wetland plants, or their symbionts, synthesize copper $(\mathrm{Cu})$ nanoparticles in their rooting zone when grown in contaminated soils, thereby reducing $\mathrm{Cu}$ uptake. Dissimilatory metal-reducing bacteria even respire on iron oxide nanoparticles in anaerobic environments (Bose et al., 2009). As analytical tools for the detection of nanoparticles improve, we may find that biogenic nanoparticles are ubiquitous and biogeochemically vital across the living planet.

Finally, through desertification, biomass burning, industrial combustion, engine exhaust, mining, and other anthropogenic activities, humans have vastly increased the global supply and variety of incidental nanoparticles, that is, those nanoparticles unintentionally produced by humans. Like the engineered nanoparticles they inspired, many of these natural and incidental nanomaterials possess unique properties that contribute disproportionately to environmental chemistry.

\section{Increasing Quantities and Diversity of Engineered Nanoparticles}

Engineered nanoparticles are defined simply as any intentionally produced particle that (i) has a characteristic dimension between
1 and $100 \mathrm{~nm}$, and (ii) possesses properties that are not shared by nonnanoscale particles with the same chemical composition (USNTC, 2004). The second part of this definition recognizes that as a result of their small size, nanomaterials possess unique properties. This is particularly true for nanoparticles $<20$ to 30 $\mathrm{nm}$ in size, which are generally characterized as having an excess of energy at the particle surface that makes them highly reactive and thermodynamically unstable (Auffan et al., 2009). What's new about ENPs is that, unlike their naturally occurring and incidentally formed counterparts, which are heterogeneously formed and diffusely dispersed in the environment, the emphasis in ENP production is to generate pure suspensions or powders consisting entirely of nanoparticles that are as homogeneous in size, shape, and structure as possible. Those nanomaterials that have the most unique characteristics (e.g., the fluorescence properties of quantum dots, the tensile strength of carbon nanotubes [CNTs], the photocatalytic properties of $\mathrm{TiO}_{2}$ ) have proven to be the most economically profitable (Wiesner et al., 2009). The race for patents and new markets puts industry under pressure to select ENPs that are truly unique and that possess previously unknown chemical properties, and to produce these novel ENPs in large quantities. Thus, the characteristics that make many ENPs worthwhile to produce are the very same qualities that make it most difficult to predict the fates and impacts of these materials in the environment (Wiesner et al., 2009). Engineered nanoparticles allow truly novel chemical reactions that are previously unknown in nature to occur (Owen and Handy, 2007); therefore, making predictions about their impacts requires significant, multidisciplinary advances.

\section{Historical Analogues?}

There is, at present, no evidence to suggest that any ENP is a significant environmental hazard (Royal Commission, http:// www.rcep.org.uk/ [verified 8 Sept. 2010], 2008), although a number of laboratory trials have measured acute toxicity and sublethal effects of ENPs on organisms (reviewed by Kahru and Dubourguier, 2009). Yet, the absence of evidence should not be taken as proof that environmental impacts will not occur. As a community, ecologists are primed to be concerned about the consequences of new technologies for the environment. One need only mention asbestos, tetraethyl lead, DDT and PCBs, or chlorofluorocarbons to conjure up the lung disease, lead poisoning, bird population declines, contaminated fisheries, and Antarctic ozone hole environmental disasters caused by these technological innovations (Rattner, 2009; Rowland, 1991). As we begin to imagine the potential ENP pollution scenarios associated with the anticipated nanotechnology revolution, we might benefit from asking ourselves: What historical analogs might allow us to best prepare for the emerging issue of ENP additions to the environment? This question is complicated by the fact that there are a wide variety of commercially important ENPs that have different levels of toxicity and which are predicted to enter the environment through a variety of alternative pathways (Fig. 1 and Table 1).

Some of the initially obvious analogies (e.g., pesticides) appear inappropriate on closer scrutiny because many historic contaminants were applied intentionally to large areas of the landscape in high, pure doses. This may be an appropriate analog for the small number of places where zero-valent iron is being injected into 
heavy metal-contaminated sites (Yantasee et al., 2007), but is a poor analog for most currently manufactured ENPs, which are likely to enter the environment inadvertently. The exposure scenario for historic lead and modern cerium oxide $\left(\mathrm{CeO}_{2}\right)$ ENP fuel additives are very similar, though a formal comparison of their chemical characteristics, transport, and toxicity is necessary to determine how far the analogy can be stretched. Carbon nanotubes appear to cause health effects similar to asbestos when they come into contact with lung epithelia (Poland et al., 2009), but it is less clear what effect CNTs will have when they are present at low concentrations in soils, sediments, and natural waters. For CNTs and many other ENPs, the primary use of the nanoparticle is as a constituent of a composite material (e.g., CNTs in vehicle tires) and these ENPs will enter the environment together with co-occurring chemicals only as the products containing them are degraded (in road runoff, landfill leachates, and wastewaters). For still other ENPs on the market, the constituent materials are themselves expensive or the fabrication conditions require such extreme precision and highly specialized facilities, making them very expensive to produce and thus unlikely to enter the environment in large quantities (e.g., gold or platinum nanoparticles and quantum dots). Risk assessment scenarios (Table 1) suggest that the majority of ENPs are going to enter the environment as part of complex waste streams in which the ENPs are present in low concentrations. Thus, the likely environmental exposure scenarios for ENPs are more similar to other emerging contaminants such as pharmaceuticals, personal care products, or flame retardants, which enter the environment as constituents of complex solid and liquid waste streams.

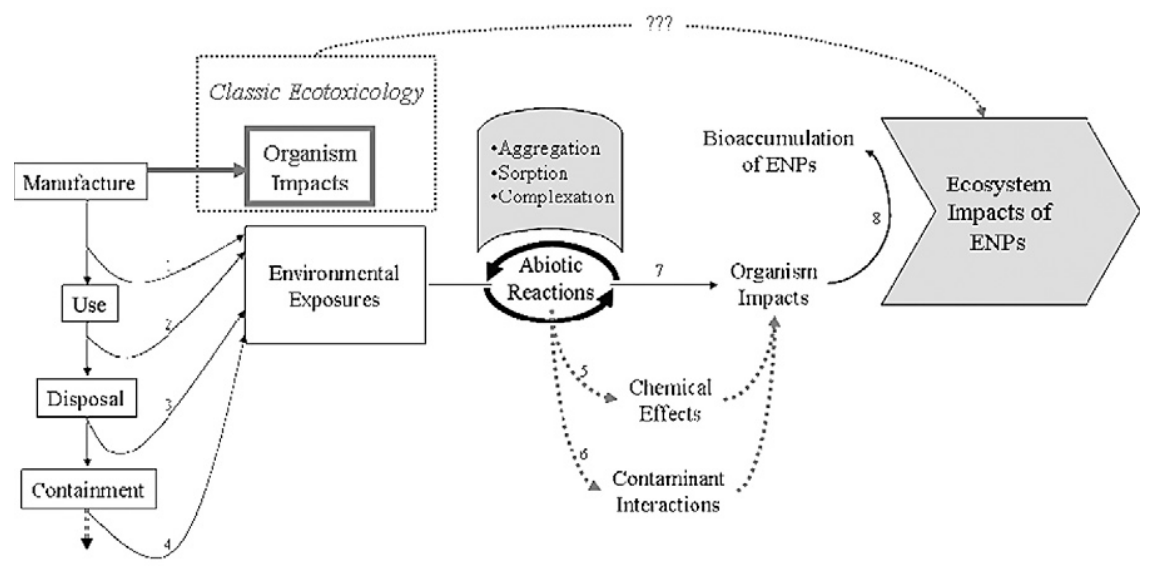

Fig. 1. We recognize that engineered nanoparticles (ENPs) can enter the environment directly through intentional environmental additions (e.g., zero-valent Fe for remediation [Yantasee et al., 2007]) or unintentional spills: ' ${ }^{1}$ as the waste byproducts of ENP manufacture; ${ }^{2}$ through the liquid waste stream as they are leached from industrial and consumer products; ${ }^{3}$ as constituents of solid wastes from biosolids; and ${ }^{4}$ through landfill leaching of disposed products or biosolids. Once ENPs enter the environment, their impact on organisms will be mediated by abiotic reactions that influence their solubility, shape, and chemistry. Engineered nanoparticles that remain soluble or that are in high concentrations in the environment are more likely to have ${ }^{7}$ direct effects on the organisms they encounter. Engineered nanoparticles may also ${ }^{5}$ indirectly affect organisms by altering the chemical environment or by ${ }^{6}$ increasing or decreasing the solubility, transport, or membrane transfer of co-occurring contaminants. Regardless of whether any organism experiences lethal or sublethal effects, if the ENP is incorporated into tissues or into detritus it is susceptible to ${ }^{8}$ trophic transfer and bioaccumulation into higher trophic levels. The vast majority of ecotoxicological studies of ENP effects to date have looked at model organism responses to pure solutions of manufactured ENPs. Such studies, though essential, are insufficient to predict the ecological impacts of the much wider range of likely exposure scenarios.

Predicting the ecological impacts of ENPs is even more complicated than predicting the impacts of other emerging organic contaminants. The quantitative structure-activity relationship (QSAR) methodology is typically used to predict the toxicity of new organic contaminants. With QSAR the similarity of a new contaminant to other known contaminants can be used to make initial predictions about its effects (Bender and Glen, 2004). Such classic characterization approaches are ultimately limited by their inability to categorize the novel physical and chemical properties of ENPs. While we can develop analogies for modern ENPs from historic contaminants with respect to

Table 1. Published risk assessment studies of engineered nanoparticle (ENP) exposure scenarios.

\begin{tabular}{|c|c|c|}
\hline Focal ENP(s) & Context & Citation \\
\hline Nanosilver (nano-Ag) & Fate and risks for aquatic exposure associated with Ag in plastics and textiles & Blaser et al., 2008 \\
\hline Nanosilver (nano-Ag) & $\begin{array}{l}\text { Comprehensive synthesis of Ag production and future likely scenarios of } \\
\text { exposure }\end{array}$ & Luoma, 2008 \\
\hline Nano- $\mathrm{TiO}_{2}$ & Assessment of $\mathrm{TiO}_{2}$ production and exposure scenarios & Ogilvie-Robichaud et al., 2009 \\
\hline Single-walled carbon nanotubes (CNTs) & $\begin{array}{l}\text { Measured the elemental, molecular, and stable carbon isotope compositions } \\
\text { of commercially available single-walled CNTs to provide unique } \\
\text { "fingerprints" to trace CNTs in the environment }\end{array}$ & Plata et al., 2008 \\
\hline $\begin{array}{l}\text { Assorted ENPs, with emphasis on } \\
\text { zero-valent Fe nanoparticles }\end{array}$ & Review of potential and risks associated with nanoremediation approaches & Karn et al., 2009 \\
\hline $\begin{array}{l}\text { Hypothetical ENPs possessing different } \\
\text { characteristics }\end{array}$ & Application of multicriteria decision analysis tools to four hypothetical ENPs & Linkov et al., 2007 \\
\hline ENPs in nanocomponents and products & Examination of industrial reporting & Meyer et al., 2009 \\
\hline Nano-Ag, nano- $\mathrm{TiO}_{2}$, and CNTs & Substance flow analysis from products to air, soil, and water in Switzerland & Mueller and Nowack, 2008 \\
\hline $\begin{array}{l}\text { Single-walled CNTs, buckyballs }\left(\mathrm{C}_{60}\right) \\
\text { quantum dots, and alumoxane and } \\
\mathrm{TiO}_{2} \text { nanoparticles }\end{array}$ & $\begin{array}{l}\text { Assessment of inputs, outputs, and waste streams in fabrication processes. } \\
\text { Comparison of risk to other industrial manufacturing processes }\end{array}$ & Robichaud et al., 2005 \\
\hline $\mathrm{TiO}_{2}, \mathrm{ZnO}, \mathrm{Ag}$, and CNT and fullerenes & $\begin{array}{l}\text { Modeled predictions of ENP concentrations in sediment and sludge treated } \\
\text { soil for the United States, Europe, and Switzerland. Risk assessment } \\
\text { scenarios compared with toxicity to calculate risk quotients }\end{array}$ & Gottschalk et al., 2009 \\
\hline
\end{tabular}


their QSAR characteristics and routes of exposure, we need to develop new ways to also categorize the novel functionalities of ENPs. In a 2009 report by the Woodrow Wilson Center, Davies stated the problem very succinctly:

Even first-generation nanotechnologies challenge traditional risk assessment methods. Multiple characteristics contribute to the toxicity of many nanomaterials; they include not just mass or number of particles but also the shape of the particles, the electrical charge at the particle surface, the coating of the particle with another material and numerous other characteristics. Science has yet to determine which of these characteristics are most important under what circumstances, and determining this will not be easy.

(Davies 2009, p. 17)

Because the diversity of ENPs is high and growing rapidly, we suggest that initial ecological research on ENP impacts should focus on ENPs that are likely to enter the environment in large quantities and that exhibit measurable toxicity in ecotoxicological testing.

\section{Known Biological Impacts}

To date, research on the biological impacts of ENPs has primarily consisted of controlled lab studies of cell cultures and model organisms exposed to high concentrations of nanomaterials in culture media (Fig. 2 and Supplemental Information). Because environmental exposures are likely to be at much lower concentrations in an ecosystem that is both physically and chemically more complex than a flask or petri dish, these studies are of only limited utility in predicting the impacts of ENPs under likely environmental exposure scenarios. An ISI Web of Science search reveals that of the $~ 98,000$ published studies of nanomaterials or nanoparticles published over the last decade only $~ 3000$ of these articles include information about nanomaterial toxicity or toxicology (Table 2 and Fig. 2) and only $\sim 150$ of those articles also include a reference to the "environment" or "ecology." From a careful survey of this literature, and papers cited within, we conclude that there are fewer than 12 published reports of the effects of an engineered nanomaterial that are ecological in design, in that they (i) include more than one species in the same experimental trial or (ii) they examined organismal responses in environmental media (i.e., natural soil, sediment, surface or groundwaters) (Table 2). The rare and notable studies to date that have examined the effects of ENP exposures on diverse ecological communities have not documented any significant increases in mortality or alterations in community structure as a result of ENP exposures (Tong et al.,
ISI Web of Science Search, September 28, 2009

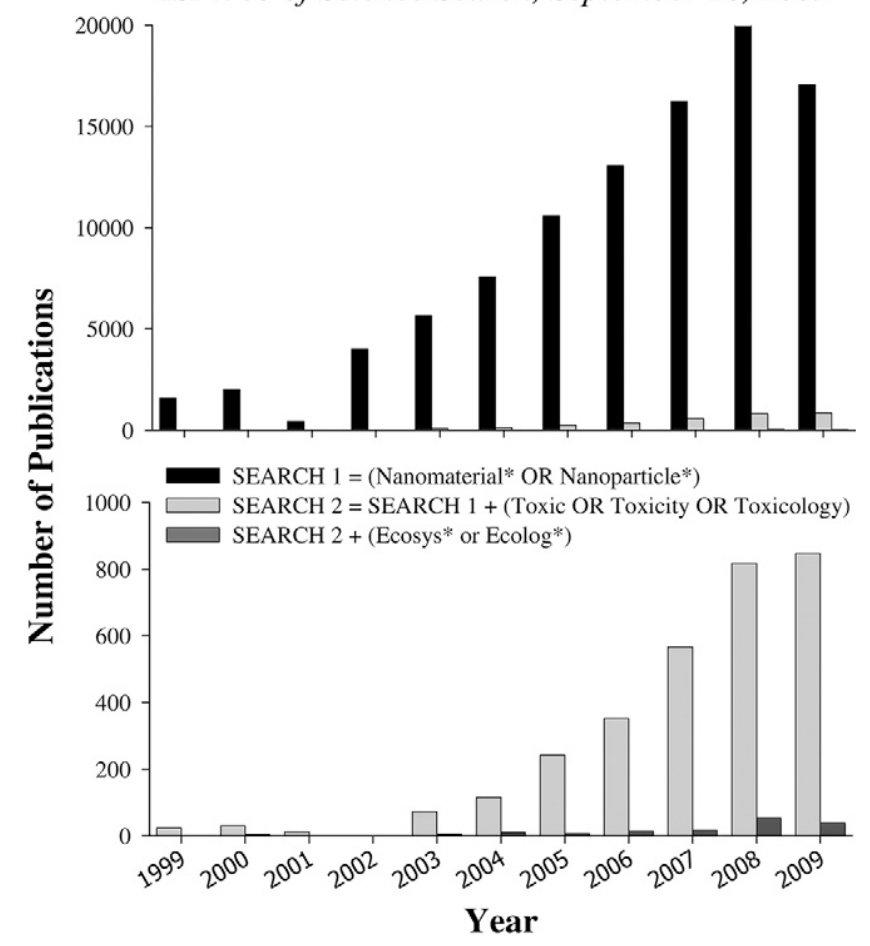

Fig. 2. Results of an ISI Web of Science search comparing the total growth in nanomaterial- and nanoparticles-related publications to publication records that also include information on toxicity or environmental impacts.

2007 [ $\mathrm{C}_{60}$ ]; Holbrook et al., 2008 [quantum dots]; Bradford et al., 2009 [nanosilver]; Ferry et al., 2009 [nanogold]).

The vast majority of nanomaterials impact research published to date has been conducted with model organisms, in experiments in which ENPs are added in the suspended state to very simple media (Supplemental Information). From such studies of pure, recently manufactured ENP exposures on model organisms, we are gaining information about the bioavailability and toxicity of ENPs to organisms growing in water or in simple growth media under highly controlled conditions (see reviews by Baun et al., 2008; Kahru and Dubourguier, 2009; Klaine et al., 2008; Navarro et al., 2008). A large number of laboratory trials have detected acute toxicity of many ENPs for diverse taxa (Fig. 3 and Supplemental Information). Yet these exposure scenarios bear little resemblance to realistic exposure scenarios-and are thus of only limited value in formulating ecological impact predictions. As fate and transport studies increasingly make it clear that most ENPs will enter the environment having undergone some degree of surface modification, and as risk assessment efforts provide more

Table 2. Results of ISI Web of Science Search and Literature Scan for articles on nanomaterials. Search conducted on 28 Sept. 2009.

\begin{tabular}{|c|c|c|c|c|c|c|c|}
\hline Search term & ALL & AND Silver & $\begin{array}{l}\text { AND Carbon } \\
\text { Nanotube }\end{array}$ & $\begin{array}{l}\text { AND Titanium } \\
\text { or } \mathrm{TiO}_{2}\end{array}$ & $\begin{array}{l}\text { AND Cerium } \\
\mathrm{OR} \mathrm{CeO}_{2}\end{array}$ & $\begin{array}{l}\text { AND Fullerenes } \\
\text { OR C }_{60} \text { OR C }_{50}\end{array}$ & $\begin{array}{l}\text { AND Zinc or } \\
\mathrm{ZnO}_{2}\end{array}$ \\
\hline Nanomaterial* OR Nanoparticle* & 98,462 & 9,158 & 7,479 & 7,702 & 1,056 & 1,089 & 3,201 \\
\hline $\begin{array}{l}\text { (Nanomaterial* OR Nanoparticle*) }+ \text { (Toxic } \\
\text { OR Toxicity OR Toxicology) }\end{array}$ & 3,076 & 179 & 482 & 338 & 32 & 165 & 133 \\
\hline $\begin{array}{l}\text { (Nanomaterial* OR Nanoparticle*) }+ \text { (Toxic } \\
\text { OR Toxicity OR Toxicology) }+(\text { (Ecosys* or } \\
\text { Ecolog*) }\end{array}$ & 147 & 19 & 41 & 46 & 3 & 39 & 10 \\
\hline $\begin{array}{l}\text { Within Search 3: Interaction between } \\
\text { organisms or between organisms and } \\
\text { natural environment }\end{array}$ & $<10$ & 1 & 3 & 1 & 0 & 4 & 0 \\
\hline
\end{tabular}


realistic scenarios of environmental exposures, we should begin to shift the emphasis of nanoecotoxicological research toward maximizing environmental relevance (Table 1 and Fig. 1). This means: (i) examining the effects of weathered, aggregated, and complexed ENPs and ENP manufacturing byproducts on a diversity of organisms; (ii) building mechanistic models of the fate and transport of ENPs in real environmental media (soils, sediments, and fresh and saline waters); and (iii) performing ENP exposure experiments in complex systems under field-relevant conditions (approximate dosing scenarios that are consistent with the best available risk assessments).

Ecotoxicological studies need to expand to include a wider diversity of functional groups. At present we find that there are several major taxonomic groups within ecological systems that are underrepresented or unrepresented within nanotoxicology. There are very few published studies of ENP effects on fungi and no studies to date on aquatic macrophytes, predatory organisms, or terrestrial herbivores. All current published studies of ENP effects on vascular plants have been conducted under highly unrealistic hydroponic growth conditions. The most well studied taxonomic group is bacteria; however, here nearly $50 \%$ of studies reporting ENP impacts on bacteria have been conducted with a single species (Escherichia coli).

\section{Experimental Challenges}

\section{Dosing}

As ENP research puts a greater emphasis on environmental relevance, we need to create experimental exposure scenarios that are not just likely to occur, but that also use concentrations that are realistic. Most work to date has involved exposures at nanoparticle concentrations that greatly exceed the highest predicted exposure scenarios (Mueller and Nowack, 2008; Gottschalk et al., 2009). For example, the latest risk assessment for silver nanoparticles suggests that the maximum concentrations we are likely to see in aquatic systems is $0.1 \mu \mathrm{g}$ nano $\mathrm{Ag}$ $\mathrm{L}^{-1}$ (Luoma, 2008; Gottschalk et al., 2009), yet most aquatic ecotoxicology studies add nano $\mathrm{Ag}$ in doses measured in $\mathrm{mg}$ $\mathrm{L}^{-1}$. When dose-response curves are used in which the lowest concentrations are far above realistic exposure scenarios, these studies are of limited utility in predicting the impacts of ENP exposures in the field because one must extrapolate the relationship between exposure and toxicity far outside of the range of available data (Fig. 4).

The use of unrealistically high concentrations for toxicity tests is a common criticism of ecotoxicological studies that is not unique to ENP research; however, because of the unique characteristics of ENPs such $\mathrm{LC}_{50}$ testing may introduce a larger number of artifacts. For instance, the toxicity of ENPs seems to be inversely related to their size (Auffan et al., 2009) and many ENPs form large aggregates when they are present at high concentrations (Baalousha, 2009; Phenrat et al., 2007). For ENPs with these dynamics, higher dosing could theoreti- cally reduce the bioavailability and toxicity of ENPs (Fig. 4, Scenario C). This is a problem not just of dosing level, but also of dosing timing. The vast majority of studies to date have used a single pulsed input of ENPs, rather than chronic dosing exposure scenarios, although most risk assessment scenarios suggest that nanomaterial exposures will involve chronic additions of low concentrations (Mueller and Nowack, 2008; Gottschalk et al., 2009). As ecological studies of ENPs commence, it is

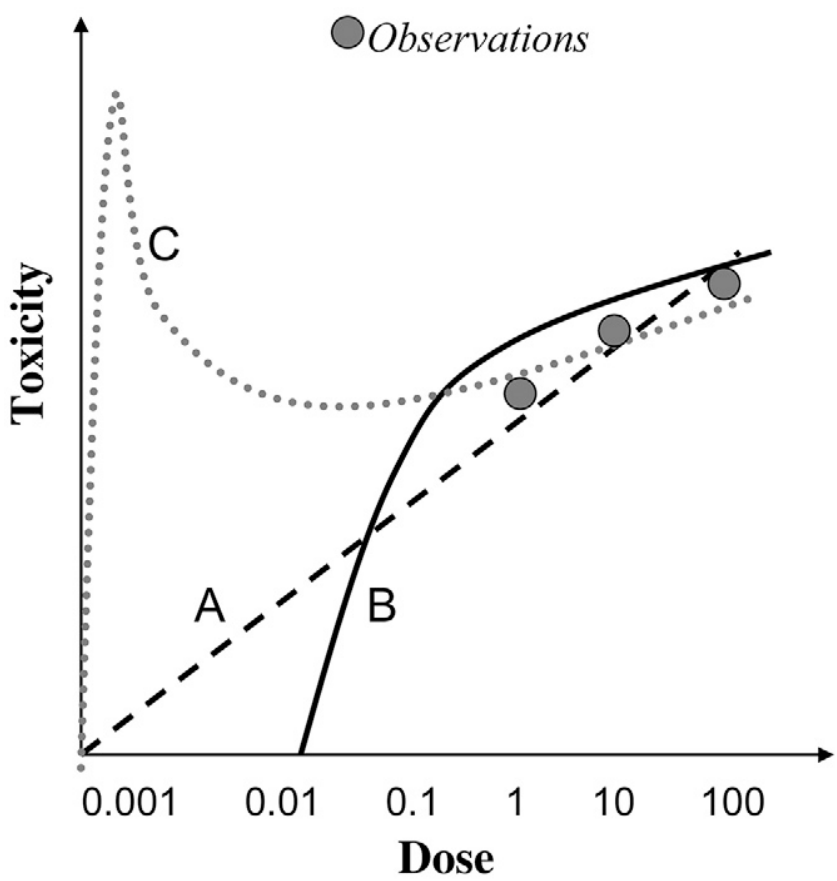

Fig. 4. Hypothetical dose-response relationships between engineered nanoparticle (ENP) concentration and some measure of toxicity. The red dots represent actual hypothetical observations while the three grayscale lines represent possible dose responses fit to the observations. Scenario A represents a case for a contaminant whose toxicity increases linearly with concentration. Scenario B represents a contaminant that is nontoxic or even beneficial at low concentrations that becomes toxic above some threshold level (e.g., many trace metals). Scenario $C$ represents a potential dose-response curve for an ENP that aggregates as particle density increases such that its toxicity is strongly ameliorated at high concentrations. 
important that we design our experimental treatments based on available risk assessments (Table 1) or, when those are not available, on well-informed and well-documented estimates of nanoparticle waste production (Bystrzejewska-Piotrowska et al., 2009). While it may be necessary, useful, and expedient to perform initial trials at high ENP addition rates to understand the mechanisms of toxicity and to refine future tests, it is critically important that realistic dose scenarios be part of any study designed to predict ecological impacts.

Once dosing scenarios have been determined, critical decisions must be made about how best to introduce ENPs into the experimental system and how to accurately measure the fate, transport, and physical and chemical transformations of ENPs over the course of experiments to adequately characterize exposure scenarios. Here, we are severely hampered by analytical limitations. For many ENPs it is not yet possible to detect nanoparticles in complex media except at exceedingly high concentrations-and thus it is often impossible to ascertain the fate of ENPs once they are added to an experimental system. In experiments where ecological impacts are measurable, an inability to ascertain the fate, transport, and transformation of the originally added ENPs may make it impossible to differentiate between direct effects of the nanoparticles and indirect effects caused by components released from the original ENP. When effects are not measured, it is impossible to ascertain which environmental mechanisms act to "protect" biota from ENP toxicity whether it be via simple aggregation of ENPs into less reactive large particles, sorption of ENPs onto organic matter or soil minerals, or dissolution of ENPs into constituent solutes. Thus, the ability to formulate mechanistic explanations about ENP effects during ecological experiments is seriously constrained at present by analytical limitations. These problems are only exacerbated in realistic exposure scenarios where ENPs are added at low doses or as constituents in complex waste mixtures such as sewage sludge or wastewater effluents (Gottschalk et al., 2009).

\section{Priorities for Research}

\section{What Do We Need to Know to Predict Environmental Impacts?}

To predict the ecosystem impacts of any particular nanomaterial, it will be necessary to consider: (i) the form, the route, and the mass of nanomaterials entering the environment (characterization and risk assessment); (ii) the fate and transport of nanomaterials in environmental media (bioavailability); (iii) organismal responses to nanomaterial exposure (ecotoxicology); and (iv) the effects of nanomaterial inputs on ecological communities and biogeochemical processes. Making progress within the first three areas requires significant interdisciplinary collaboration among social scientists, chemists, engineers, and toxicologists, and is a necessary platform on which any ecological research must be built. Ecologists can play an important role within these disciplines by providing ecological insights and expertise to ensure that our colleagues in other disciplines collect the kinds of data necessary to underpin ecological investigations. We need to push nanochemists and engineers to study the fate and transport of ENPs in real environmental media, and to refine existing visualization and measurement approaches to facilitate the detection of ENPs in complex media. We should be both conducting and promoting active laboratory research that supplements existing toxicological studies by measuring ENP impacts on nonmodel organisms and on mixed communities of organisms (e.g., complex microbial communities). We should also initiate top-down experiments in which ENPs are added to field-relevant experimental systems that provide us with opportunities to observe unanticipated environmental impacts.

Field research is badly needed to help guide ENP research. In the extremely limited literature available at this time, the significant ENP toxicity measured in pure culture studies has not been found in field-relevant studies with mixed communities in natural media. For example, there are numerous published reports of silver nanoparticle and $\mathrm{C}_{60}$ toxicity to microbes from pure culture studies (Table 2 and reviewed by Klaine et al., 2008; Neal, 2008). In the two published experiments to date in which high concentrations of both materials were added to sediment or soil containing natural microbial communities, the ENPs caused no detectable changes in microbial biomass, activity, or community structure $\left(\mathrm{C}_{60}-\right.$ Tong et al., 2007; nano $\mathrm{Ag}$ - Bradford et al., 2009). In both studies, researchers concluded that the nanoparticles sorbed to soil/sediment particles and were consequently unavailable to bacteria. In toxicological tests of nano Ag toxicity for the zooplankton Ceriodaphnia dubia in natural river water, toxicity was found to be strongly altered by both dissolved organic carbon concentrations and ionic strength (Gao et al., 2009). Even in pure culture experiments, abiotic interactions with culture media play an important role in influencing toxicity; for example, Thill et al. (2006) reported that $\mathrm{CeO}_{2}$ nanoparticles were highly toxic to E. coli in pure water, but later found that they had no effect on $E$. coli in culture media because the $\mathrm{CeO}_{2}$ nanoparticles formed large aggregates (Thill et al., 2009). For many of these highly reactive ENPs, interactions with soil and organic matter surfaces may substantially mitigate their bioavailability. Similarly, most ENP toxicological studies on plants (reviewed by Monica and Cremonini, 2009; Navarro et al., 2008) have been conducted in hydroponic systems and thus are hard to relate to natural systems. Thus, field experiments for some ENPs may substantially temper our concerns about their impacts and generate important new questions about the biogeochemical mechanisms that either reduce organismal exposure or reduce ENP toxicity.

Although there is no published evidence to date, it is also likely that we will discover that some ENPs exhibit enhanced bioavailability and/or toxicity in natural environments relative to what is measured in controlled laboratory settings. For example, Mahendra et al. (2008) found that quantum dots were nontoxic to Bacillus subtilis and E. coli at the near-neutral $\mathrm{pH}$ characteristic of culture media, but became highly toxic after exposure to environmentally relevant acid or alkaline solutions weathered off the quantum dots' organic coatings, exposing organisms directly to the cadmium and selenium atoms of the quantum dots. Still other ENPs may show no toxicity to primary consumers but generate toxicity through bioaccumulation into higher trophic levels. Li et al. (2008) showed that Medaka fish [Oryzias latipes (Temminck and Schlegel)] accumulated up to $6 \times$ more Se in their livers and 
experienced greater oxidative stress in incubations with nanoSe than in incubations with larger Se particles. For ENPs that become more toxic through environmental weathering, chemical reactions, or through consumption or alteration by organisms, empirical evidence from extended-duration, fieldrelevant trials will be critical for establishing the need for and guiding regulation of such ENPs.

\section{Proceeding in the Face of Uncertainty-How Can We Build a Nano-Ecological Research Program Able to Keep Pace with the Exponential Growth in Nanotechnologies?}

Although ENPs possess unique characteristics, many of the inherent challenges of understanding the impacts of a new stressor on organisms and ecosystems are in fact classic problems in ecology that have been debated extensively in the literature. Ecological experiments performed with ENPs will benefit from some consideration of these debates.

\section{Model Systems vs. Reality}

In ecology, we often work across four scales of inquiry for experimental studies: highly simplified bottle assays that isolate components of ecological communities; microcosms that incorporate some degree of environmental heterogeneity within closed systems; mesocosms intended to create "smaller working versions of ecosystems" in field containers; and field experiments, where intact ecosystems are manipulated and studied. There has been extensive debate about the value of microcosms in ecological research due to their inherent simplicity and small scales. At the same time, observational studies or whole-system manipulations are limited due to their lack of control, low replication, and general inability to explain mechanism. To understand the impacts of nanoparticles on ecosystems, we need studies that are specifically designed to be complementary across scales. We need the small, highly replicated microcosm studies in which we can thoroughly understand mechanisms and test basic theory. Small-scale laboratory experiments should be used not only for their tight control and resulting ability to detect mechanisms, but also for their utility in screening a wide variety of ENPs to prioritize and strategically design longer and replication-limited mesocosm and field-scale experiments. Mesocosm and field-scale experiments are needed that incorporate multiple trophic levels, are open to colonization, and allow some degree of community adaptation. These larger, open systems also experience natural environmental variability, which may generate ecosystem responses that would not be anticipated based on controlled laboratory studies. Because they are larger in size, so-called "cage artifacts" are less pronounced and experiments can be of longer duration, allowing for chronic addition studies and the potential for looking at longer-term dynamics.

\section{Organism Evolution and Community Adaptation}

We now know that evolution happens more rapidly than we ever thought possible, in some cases within a single season or even a single generation (Hairston et al., 2005). As a result, many ecological phenomena are influenced by adaptation over very short time scales. Adaptation has the potential to modify how organisms respond to, as well as influence, (i) the toxicity of ENPs, (ii) the potential for bioaccumulation, and possibly (iii) rates of bio- magnification. Therefore, experiments-whether performed at the scale of microcosms or whole systems - would benefit greatly by running sufficiently long to allow for and measure the adaptive responses of the focal organisms.

\section{Food Web Complexity}

To date only one published ENP exposure study has explicitly included more than two trophic levels within a study. Holbrook et al. (2008) found that quantum dots attached to the cell membranes of $E$. coli were consumed by ciliate bacterivores, which were subsequently consumed by rotifers. Although these short-duration assays confirmed the potential for trophic transfer observed in a limited number of prior studies, the authors found no measurable toxicity or evidence for bioaccumulation. More such studies are necessary to help resolve concerns about ENP bioaccumulation and biomagnification through food webs. These studies must examine not only whether transfer and bioaccumulation of ENPs occurs-but also pay close attention to whether ENPs are stored or processed within organism tissues in unique ways that may affect their toxicity or transfer efficiency. The difficulty of including trophic realism in experiments is a perpetual problem. There clearly is no prescribed level of complexity that should be advocated in nanoparticle studies, yet numerous ecological studies in the past have shown that (i) indirect interactions among species can be at least as important in moderating the response of a community to a stressor as direct interactions; (ii) rare, seemingly insignificant species frequently exhibit compensatory dynamics following a disturbance that lead to their becoming major players in a food web; and (iii) trophic cascades have the potential to completely alter conclusions about how much and how rapidly ENPs accumulate within various components of the food web. Ecologists will no doubt begin their studies of ENPs using trophically simple systems. While this is reasonable, conclusions should always be tempered with the above caveats in mind, and researchers should always strive to add the next level of trophic realism to their work.

\section{Multiple Stressors}

Most studies of disturbance, including much of ecotoxicology, are designed to test individual stressors one at a time. Yet, in the real world stressors rarely occur alone. Ecosystems are bombarded with numerous types of potential toxicants, many of which have the potential to interact in a nonadditive way. In addition, the response of ecosystems to potential toxicants is multivariate, with many correlated response variables changing simultaneously, and sometimes nonlinearly. Therefore, we need to focus on the development and testing of multivariate models of causality from the beginning of ecological research on ENPs. While it may be initially useful to examine the simplest cases where ENP $x, y$, or $z$ impacts response $a, b$, or $c$, what we ultimately need to have is a model that predicts how ENPs $x+y+$ $z$ concurrently impact $a+b+c$. For ENPs this is particularly important. There is growing recognition that most nanoparticles will enter the environment through waste streams in which they will be mixed with a variety of co-occurring contaminants. Because of their high reactivity, the potential exists for ENPs to alter the transport or bioavailability of other compounds, an especial concern given their likely co-occurrence with other pollutants (e.g., Cai et al., 2005; Kersting et al., 1999). For 
example, Zhang et al. (2007) found that $\mathrm{TiO}_{2}$ nanoparticles facilitated $\mathrm{Cd}$ accumulation in carp (Cyprinus carpio L.) during bioaccumulation studies as compared with natural sediment particles. Baun et al. (2008) found that the addition of $\mathrm{C}_{60}$ fullerenes increased the toxicity of phenanthrene and decreased the toxicity of pentachlorophenol to algae. Both of these studies suggest that ENPs may have both antagonistic and synergistic interactions with co-occurring contaminants in addition to any inherent toxicity. These interactions can occur because of the unique chemistry or the unique shape of the ENPs.

\section{Modeling Approaches Allow Detection of Sublethal Effects}

An inherent challenge for ecologically relevant experiments (more than one species and/or "realistic" doses and environments) on toxic effects caused by ENPs is the likelihood of finding small effects with high variability. Also, the data obtained will involve different organizational levels (molecules, cells, organisms, populations, ecosystems). Thus, design and interpretation of experiments must focus on identifying the key processes involved in toxicity and trophic transfer. This is a long-recognized challenge for ecotoxicology, one that has been approached through a broad range of pragmatic and/or modelbased methodologies. Reviewing these is beyond the scope of this paper; instead, we highlight one approach that is attracting growing interest, the use of Dynamic Energy Budget models.

Dynamic Energy Budget (DEB) theory is a powerful theoretical framework for relating suborganismal (biochemical, genetic, physiological) processes to organismal performance and, thereby, to populations, ecosystems, and their evolution (Kooijman, 2010; Nisbet et al., 2000). Central to DEB theory are assumptions regarding the regulation of the composition of living organisms (homeostasis assumptions). The approach initially focuses at the level of the individual organism. Dynamic models describe the rates at which the organism assimilates and uses energy and elemental matter from food for its maintenance, growth, reproduction, and development, the rates of which depend on the state of the organism (e.g., age, size, maturity) and its environment (e.g., food density, temperature). A population is then regarded as a collection of individuals each obeying the rules of the DEB model, with all individuals sharing a common environment. Given a DEB model that characterizes individual responses to the environment, there are well-established techniques for modeling simple lab populations (e.g., Tuljapurkar and Caswell, 1997).

Dynamic Energy Budget theory has been previously shown to be a powerful tool for ecotoxicology (Kooijman et al., 2009; Kooijman and Bedaux, 1996; Muller et al., 2010). Such applications require additional assumptions that describe the uptake, release, and metabolism of toxic compounds, and the effects of the toxicants on the organism's physiology; specifically, toxicokinetic and toxic effect submodels are required (Kooijman et al., 2009; Muller et al., 2010). The toxicokinetic submodels describe contaminant exchange with the environment and chemical transformations within an organism. The toxic effect submodel specifies how the basic DEB model parameters change in response to the toxicant. Using DEB theory to predict the consequences of introducing nanoparticles follows similar principles, but with the additional requirement to take account of the impact of the ENPs on the "environment" experienced by the focal organisms and simultaneously to account for the "environmental filter" that modifies the solubility, reactivity, and structure of ENPs.

\section{Prepare from the Beginning for Synthesis}

As ecologists begin individual experiments looking at how ENPs impact various systems, we believe it is in the best interest of our discipline to prepare in advance for the syntheses of data that are likely to take place within the next decade. While many forms of data synthesis exist, meta-analysis has become one of, if not the most prominent form of statistical synthesis (Osenberg et al., 1997). Gurevitch et al. (1992) introduced meta-analyses to ecologists as a statistical means of assessing the generality of pattern and process among studies. Meta-analyses was defined by Glass (1976, p. 3) as "the statistical analysis of a large collection of analysis results for the purpose of integrating the findings" and typically involves converting quantitative responses to a treatment from component individual studies into response ratios or effect sizes that can be compared and compiled across studies (Hedges et al., 1999). The main advantages of meta-analysis over other forms of synthesis are that (i) the method allows for quantification of treatment effect sizes that can be readily compared across studies even when those studies have been performed using different methods, and (ii) meta-analysis can explicitly account for key differences among studies in the statistical model, allowing us to ask questions about which factors cause effect sizes to vary.

Meta-analysis is a powerful tool that ignores the details of individual studies so that we can step back and quantify effect sizes after accounting for all the random variation among studies. This broader view is essential if we are to determine what generalities exist for the impacts of individual nanoparticles on ecosystems, or what generalities exist among nanoparticles. To facilitate the possibility of future meta-analyses we must prepare now-at the beginning of the proliferation of individual studies — by: avoiding publication bias, making data sets available in repositories, and reporting all potentially relevant details of the experimental details.

The tendency to not publish studies simply if they found insignificant or negative results has been one of the single biggest factors limiting data syntheses. Although there are statistical methods to detect such "publication bias," there is little that can be done to correct it if found to exist. Researchers, reviewers, and editors need to be conscious that publication of negative results is just as vital to the future of data syntheses as publication of significant results. This is particularly important in ecological research about contaminants. We sincerely hope that many ENPs will prove to be nontoxic in the natural environment, and rigorous empirical evidence of no effects must be treated on par with the discovery of toxicity or unexpected environmental interactions.

Researchers inevitably have unique ways of summarizing and reporting their data in publications, and there is no practical way of standardizing reporting among journals. But unfortunately, our experience suggests that a large fraction of studies report results in such a way that the key pieces of data needed for a meta-analysis cannot be extracted from the paper itself (e.g., figures do not report errors, analyses are performed on grouped 
means, data-points on plots cannot be distinguished, etc.). The number of studies that can be included in future meta-analyses will be greatly increased if researchers make it commonplace to publish the data set associated with their paper, either as (i) a supplement to the paper itself (if supported by the journal), or (ii) in a public data repository, such as the Knowledge Network for Biocomplexity hosted by the National Center for Ecological Analysis and Synthesis. In the latter case, the authors can put a link to the site in their acknowledgments.

Although one goal of meta-analysis is to quantify effect sizes after accounting for random variation among studies, an often more powerful use of meta-analysis is to identify which factors are responsible for variation in effect sizes among studies. In this sense, meta-analysis has the potential to identify specific mechanisms that are linked to effect sizes. Unfortunately, the heterogeneity among studies in their reporting of experimental details is extreme. It can range from almost no detail whatsoever in journals with a short reporting format, to extensive details in journals that offer space. We would encourage researchers to make it a practice to always publish a supplement or appendix with their paper that details (i) the source, preparation, and measured physical properties of the $\mathrm{ENP}(\mathrm{s})$ used; (ii) the physical and chemical properties of the soil or water media used; (iii) the properties of the experimental units; and (iv) the properties of the focal organisms. We strongly recommend that ecologists devise a standardized list of required details that must accompany the publication of all future ENP experimental results.

\section{Play to Our Strengths}

Ecologists need to take advantage of the opportunity provided by new funding investments in environmental nanomaterials research to demonstrate how adding ecological expertise and approaches can improve our ability to predict the effects of emerging contaminants. We can play an important role in several ways. First, we can provide a critical reality check to our colleagues actively engaged in the study of ENP fate and transport and in classic toxicological studies. Together with experts in risk assessment, ecologists can and should be the voices calling for ever greater attention to realistic experimental scenarios. Second, ecologists should be deploying our unique expertise with conducting experiments in complex systems and modeling complex interactions to develop robust ecological impact assessments for the most likely types of ENP exposures. Third, we should use our expertise in observational science to develop and refine monitoring programs that will be capable of detecting ENP exposures in natural environments if and when they begin to occur.

Ultimately, there are going to be unexpected effects of ENPs in natural environments. We will not be able to provide a priori predictions of all environmental impacts from controlled laboratory studies, and we may find that laboratory outcomes cannot predict ecological outcomes in the field (as reported by Bradford et al., 2009; Tong et al., 2007). The impacts of ENPs, like those of many historic and emerging contaminants, are likely to be subtle and sublethal, to accumulate through time, or to be additive or synergistic with other contaminants. We can help guide nanomaterials science in asking the right mechanistic questions by conducting strategic, relevant ecological experiments that help us better prioritize among the many knowledge gaps about the impacts of ENPs in natural environments.

\section{Concluding Remarks}

As we work with chemists, engineers, and ecotoxicologists to provide proactive advice on the potential dangers of ENPs within the environment, we can look forward to many technological and intellectual benefits to ecological science from these collaborations. Nanotechnologies and nanoscience can provide new tools and capabilities to ecosystem science. Already, quantum dot tracers have allowed ecologists to visualize and quantify organic nitrogen uptake from soils by plants and mycorrhizae (Whiteside et al., 2009). A whole host of nano-sensors are being developed that could revolutionize our understanding of our environment (e.g., Andreescu et al., 2009; Cho et al., 2008; Chopra et al., 2002; Consales et al., 2009; Granqvist et al., 2007; Huang and Chang, 2006; Liu and Lin, 2005; Nelli et al., 1996; Park et al., 2009; Toal et al., 2005), allowing us to detect environmental conditions, gas concentrations, and contaminant loads at a temporal and spatial resolution never before possible. As the tools for nanomaterial measurement and characterization are transferred into ecology, we are increasingly recognizing that many organisms produce nanoparticles, and that these natural nanoparticles may play important roles in biogeochemical cycling (e.g., Gorby et al., 2006; Manceau et al., 2008; Blango and Mulvey, 2009).

As we progress in the study of ENPs, we sincerely hope to find that most ENPs will have no adverse effects in the environment under realistic exposure scenarios. There are real opportunities to harness the power of nanotechnology for environmental remediation and ecological research. A number of green nanotechnologies are under development. Cerium oxide nanomaterials are already being added to diesel fuels throughout Europe, and it is claimed that these combustion catalysts reduce greenhouse gas and aerosol pollution from diesel engines (SmallTimes, 2005). Zero-valent iron nanomaterials are being used around the world for the remediation of trace metal pollution in toxic waste sites (Karn et al., 2009; Li et al., 2006; Yantasee et al., 2007). Nanosilver-embedded membrane filters and disinfection through ultraviolet and $\mathrm{TiO}_{2}$ photocatalysis are proposed as more effective water and wastewater treatments for the removal of organic pollutants than current disinfection techniques (Paleologou et al., 2007; Sharma et al., 2009). Some of these nanotechnologies may help reverse environmental degradation or may replace the more toxic technologies currently in use. Others may end up substituting a new problem for an old one. It is important that we develop the scientific tests and models that can distinguish between these alternatives.

\section{Acknowledgments}

This paper arises from a series of discussions and talks at the International Conference on the Emerging Impacts of Nanomaterials held at Howard University in Washington, DC, in fall 2009. The authors would like to thank Hunter Lenihan, Josh Schimel, Claudia Gunsch, Paul Bertsch, Jason Unrine, and Trish Holden for their part in the stimulating discussions that generated this paper. The authors are funded through the Center for the Environmental Implications of Nanotechnology and through the University of California Center for the Environmental Implications of Nanotechnology. Both centers are supported by funding from the National Science Foundation (NSF) and the U.S. Environmental Protection Agency (EPA). Any opinions, 
findings, conclusions, or recommendations expressed in this material are those of the author(s) and do not necessarily reflect the views of the NSF or the EPA. This work has not been subjected to EPA review and no official endorsement should be inferred.

\section{References}

Andreescu, S., J. Njagi, C. Ispas, and M.T. Ravalli. 2009. JEM Spotlight: Applications of advanced nanomaterials for environmental monitoring. J. Environ. Monit. 11:27-40.

Auffan, M., J. Rose, J.-Y. Bottero, G.V. Lowry, J.-P. Jolivet, and M.R. Wiesner 2009. Towards a definition of inorganic nanoparticles from an environmental, health and safety perspective. Nat. Nanotechnol. 4:634-641.

Baalousha, M. 2009. Aggregation and disaggregation of iron oxide nanoparticles: Influence of particle concentration, $\mathrm{pH}$ and natural organic matter. Sci. Total Environ. 407:2093-2101.

Banfield, J., and A. Navrotsky (ed.) 2001. Nanoparticles and the environment. Reviews in mineralogy and geochemistry. Vol. 44. Mineral. Soc. of Am. Washington, DC

Bargar, J.R., R. Bernier-Latmani, D.E. Giammar, and B.M. Tebo. 2008. Biogenic uraninite nanoparticles and their importance for uranium remediation. Elements (Chantilly, VA, U. S.) 4:407-412.

Baun, A., N.B. Hartmann, K. Grieger, and K.O. Kusk. 2008. Ecotoxicity of engineered nanoparticles to aquatic invertebrates: A brief review and recommendations for future toxicity testing. Ecotoxicology 17:387-395.

Becker, L., R.J. Poreda, J.A. Nuth, F.T. Ferguson, F. Liang, and W.E. Billups. 2006. Fullerenes in meteorites and the nature of planetary atmospheres. p. 95-121. In F.J.M. Rietmeijer (ed.) Natural fullerenes and related structures of elemental carbon. Vol. 6. Springer, Dordrecht, Netherlands.

Bender, A., and R.C. Glen. 2004. Molecular similarity: A key technique in molecular informatics. Org. Biomol. Chem. 2:3204-3218.

Blango, M.G., and M.A. Mulvey. 2009. Bacterial landlines: Contact-dependent signaling in bacterial populations. Curr. Opin. Microbiol. 12:177-181.

Blaser, S.A., M. Scheringer, M. Macleod, and K. Hungerbuhler. 2008. Estimation of cumulative aquatic exposure and risk due to silver: Contribution of nano-functionalized plastics and textiles. Sci. Total Environ. 390:396-409.

Bose, S., M.F. Hochella, Y.A. Gorby, D.W. Kennedy, D.E. McCready, A.S Madden, and B.H. Lower. 2009. Bioreduction of hematite nanoparticles by the dissimilatory iron reducing bacterium Shewanella oneidensis MR1. Geochim. Cosmochim. Acta 73:962-976.

Bradford, A., R.D. Handy, J.W. Readman, A. Atfield, and M. Muhling. 2009. Impact of silver nanoparticle contamination on the genetic diversity of natural bacterial assemblages in estuarine sediments. Environ. Sci. Technol. 43:4530-4536.

Buseck, P.R., and K. Adachi. 2008. Nanoparticles in the atmosphere. Elements (Chantilly, VA, U. S.) 4:389-394

Bystrzejewska-Piotrowska, G., J. Golimowski, and P.L. Urban. 2009. Nanoparticles: Their potential toxicity, waste and environmental management. Waste Manag. 29:2587-2595.

Cai, D., J.M. Mataraza, Z.H. Qin, Z.P. Huang, J.Y. Huang, T.C. Chiles, D. Carnahan, K. Kempa, and Z.F. Ren. 2005. Highly efficient molecular delivery into mammalian cells using carbon nanotube spearing. Nat. Methods 2:449-454.

Chadwick, O.A., L.A. Derry, P.M. Vitousek, B.J. Huebert, and L.O. Hedin. 1999. Changing sources of nutrients during four million years of ecosystem development. Nature 397:491-497.

Cho, E.S., S.W. Hong, and W.H. Jo. 2008. A new pH sensor using the fluorescence quenching of carbon nanotubes. Macromol. Rapid Commun. 29:1798-1803

Chopra, S., A. Pham, J. Gaillard, A. Parker, and A.M. Rao. 2002. Carbonnanotube-based resonant-circuit sensor for ammonia. Appl. Phys. Lett. 80:4632-4634.

Consales, M., A. Crescitelli, M. Penza, P. Aversa, P.D. Veneri, M. Giordano, and A. Cusano. 2009. SWCNT nano-composite optical sensors for VOC and gas trace detection. Sens. Actuators B Chem. 138:351-361.

Crichton, M. 2002. Prey. Harper Collins, New York.

Davies, J.C. 2009.Oversight of next generation nanotechnology. Woodrow Wilson Int. Cent. for Scholars, Project on Emerging Nanotechnol. Available at http://www.nanotechproject.org/publications/archive/pen18/ (verified 8 Sept. 2010)

Eriksson, E. 1952. Cation-exchange equilibria on clay minerals. Soil Sci. 74:103-113

Ferry, J.L., P. Craig, C. Hexel, P. Sisco, R. Frey, P.L. Pennington, M.H. Fulton, I.G. Scott, A.W. Decho, S. Kashiwada, C.J. Murphy, and T.J. Shaw. 2009. Transfer of gold nanoparticles from the water column to the estua- rine food web. Nature Nanotechnol. 4:441-444.

Feynman, R.P. 1959. There's plenty of room at the bottom. Talk delivered at the annual meeting of the Am. Phys. Soc. at the California Inst. of Technol., Pasadena. 26 Dec. 1959.

Gao, J., S. Youn, A. Hovsepyan, V.L. Llaneza, Y. Wang, G. Bitton, and J.C.J. Bonzongo. 2009. Dispersion and toxicity of selected manufactured nanomaterials in natural river water samples: Effects of water chemical composition. Environ. Sci. Technol. 43:3322-3328.

Gieseking, J.E. 1939. The mechanism of cation exchange in the montmorillonite-beidellite-nontronite type of clay minerals. Soil Sci. 47:1-13.

Glass, G.V. 1976. Primary, secondary, and meta-analysis of research. Educ. Res. 5:3-8.

Gilbert, B., and J.F. Banfield. 2005. Molecular-scale processes involving nanoparticulate minerals in biogeochemical systems. Rev. Mineral. Geochem. 59:109-155.

Gorby Y.A., S. Yanina, J.S. McLean, K.M. Rosso, D. Moyles, A. Dohnalkova, T.J. Beveridge, I.S. Chang, B.H. Kim, K.S. Kim, D.E. Culley, S.B. Reed, M.F. Romine, D.A. Saffarini, E.A. Hill, L. Shi, D.A. Elias, D.W. Kennedy, G. Pinchuk, K. Watanabe, S. Ishii, B. Logan, K.H. Nealson, and J.K. Fredrickson. 2006. Electrically conductive bacterial nanowires produced by Shewanella oneidensis strain MR-1 and other microorganisms. Proc. Natl. Acad. Sci. USA 103:11358-11363.

Gottschalk, F., T. Sonderer, R.W. Scholz, and B. Nowack. 2009. Modeled environmental concentrations of engineered nanomaterials $\left(\mathrm{TiO}_{2}, \mathrm{ZnO}, \mathrm{Ag}, \mathrm{CNT}\right.$, Fullerenes) for different regions. Environ. Sci. Technol. 43:9216-9222.

Granqvist, C.G., A. Azens, P. Heszler, L.B. Kish, and L. Osterlund. 2007. Nanomaterials for benign indoor environments: Electrochromics for "smart windows", sensors for air quality, and photo-catalysts for air cleaning. Sol. Energy Mater. Sol. Cells 91:355-365.

Gurevitch, J., L.L. Morrow, A. Wallace, and J.S. Walsh. 1992. A metanalysis of competition in field experiments. Am. Nat. 140:539-572.

Hairston, N.G., Jr., S.P. Ellner, M.A. Geber, T. Yoshida, and J.A. Fox. 2005. Rapid evolution and the convergence of ecological and evolutionary time. Ecol. Lett. 8:1114-1127.

Hassellöv, M., and F. von der Kammer. 2008. Iron oxides as geochemical nanovectors for metal transport in soil-river systems. Elements (Chantilly, VA, U. S.) 4:401-406.

Hedges, L.V., J. Gurevitch, and P.S. Curtis. 1999. The meta-analysis of response ratios in experimental ecology. Ecology 80:1150-1156.

Hochella, M.F., Jr. 2002. Nanoscience and technology: The next revolution in the Earth sciences. Earth Planet. Sci. Lett. 203:593-605.

Hochella, M.F., Jr. 2008. Nanogeoscience: From origins to cutting-edge applications. Elements (Chantilly, VA, U. S.) 4:373-379.

Hochella, M.F., S.K. Lower, P.A. Maurice, R.L. Penn, N. Sahai, D.L. Sparks, and B.S. Twining. 2008. Nanominerals, mineral nanoparticles, and Earth systems. Science 319:1631-1635.

Holbrook, R.D., K.E. Murphy, J.B. Morrow, and K.D. Cole. 2008. Trophic transfer of nanoparticles in a simplified invertebrate food web. Nat. Nanotechnol. 3:352-355.

Huang, C.C., and H.T. Chang. 2006. Selective gold-nanoparticle-based "turnon" fluorescent sensors for detection of mercury(II) in aqueous solution. Anal. Chem. 78:8332-8338.

Jickells, T.D., Z.S. An, K.K. Andersen, A.R. Baker, G. Bergametti, N. Brooks, J.J. Cao, P.W. Boyd, R.A. Duce, K.A. Hunter, H. Kawahata, N. Kubilay, J. laRoche, P.S. Liss, N. Mahowald, J.M. Prospero, A.J. Ridgwell, I. Tegen, and R. Torres. 2005. Global iron connections between desert dust, ocean biogeochemistry, and climate. Science 308:67-71.

Kahru, A., and H.-C. Dubourguier. 2009. From ecotoxicology to nanoecotoxicology. Toxicology. doi:10.1016/j.tox.2009.08.016

Karn, B., T. Kuiken, and M. Otto. 2009. Nanotechnology and in situ remediation: A review of the benefits and potential risks. Environ. Health Perspect. doi:10.1289/ehp.0900793.

Kersting, A.B., D.W. Efurd, D.L. Finnegan, D.J. Rokop, D.K. Smith, and J.L. Thompson. 1999. Migration of plutonium in ground water at the Nevada Test Site. Nature 397:56-59.

Klaine, S.J., P.J.J. Alvarez, G.E. Batley, T.F. Fernandes, R.D. Handy, D.Y Lyon, S. Mahendra, M.J. McLaughlin, and J.R. Lead. 2008. Nanomaterials in the environment: Behavior, fate, bioavailability, and effects. Environ. Toxicol. Chem. 27:1825-1851.

Kooijman, S.A.L.M. 2010. Dynamic Energy Budget theory for metabolic organization. Cambridge Univ. Press, New York.

Kooijman, S.A.L.M., J. Baas, D. Bontje, M. Broerse, C.A.M. Van Gestel, and T. Jager. 2009. Ecotoxicological applications of Dynamic Energy Budget theory. p. 237-260. In J. Devillers (ed.) Ecotoxicology modeling. Emerging topics in ecotoxicology: Principles, approaches and perspectives. Springer, New York. 
Kooijman, S.A.L.M., and J.J.M. Bedaux. 1996. The analysis of aquatic toxicity data. VU Univ. Press, Amsterdam.

Kulmala, M., and V.-M. Kerminen. 2008. On the formation and growth of atmospheric nanoparticles. Atmos. Res. 90:132-150.

Li, H.C., J.S. Zhang, T. Wang, W.R. Luo, Q.F. Zhou, and G.B. Jiang. 2008. Elemental selenium particles at nano-size (Nano-Se) are more toxic to Medaka (Oryzias latipes) as a consequence of hyper-accumulation of selenium: A comparison with sodium selenite. Aquat. Toxicol. 89:251-256.

Li, X.Q., D.W. Elliott, and W.X. Zhang. 2006. Zero-valent iron nanoparticles for abatement of environmental pollutants: Materials and engineering aspects. Crit. Rev. Solid State Mater. Sci. 31:111-122.

Linkov, I., F.K. Satterstrom, J. Steevens, E. Ferguson, and R.C. Pleus. 2007. Multi-criteria decision analysis and environmental risk assessment for nanomaterials. J. Nanopart. Res. 9:543-554.

Liu, G.D., and Y.H. Lin. 2005. Electrochemical sensor for organophosphate pesticides and nerve agents using zirconia nanoparticles as selective sorbents. Anal. Chem. 77:5894-5901.

Luoma, S.N. 2008. Silver nanotechnologies and the environment: Old problems or new challenges. Woodrow Wilson Int. Cent. for Scholars, Project for Emerging Nanotechnol. Available at http://www.pewtrusts.org/ uploadedFiles/wwwpewtrustsorg/Reports/Nanotechnologies/Nano_ PEN_15_Final.pdf (verified 8 Sept. 2010).

Mahendra, S., H.G. Zhu, V.L. Colvin, and P.J. Alvarez. 2008. Quantum dot weathering results in microbial toxicity. Environ. Sci. Technol. 42:9424-9430.

Manceau, A., K.L. Nagy, M.A. Marcus, M. Lanson, N. Geoffroy, T. Jacquet, and T. Kirpichtchikova. 2008. Formation of metallic copper nanoparticles at the soil-root interface. Environ. Sci. Technol. 42:1766-1772.

Maurice, P.A., and M.F. Hochella, Jr. 2008. Nanoscale particles and processes: A new dimension in soil science. Adv. Agron. 100:123-153.

Meyer, D.E., M.A. Curran, and M.A. Gonzalez. 2009. An examination of existing data for the industrial manufacture and use of nanocomponents and their role in the life cycle impact of nanoproducts. Environ. Sci. Technol. 43:1256-1263.

Monica, R.C., and R. Cremonini. 2009. Nanoparticles and higher plants. Caryologia 62:161-165.

Mueller, N.C., and B. Nowack. 2008. Exposure modeling of engineered nanoparticles in the environment. Environ. Sci. Technol. 42:4447-4453.

Muller, E.B., R.M. Nisbet, and H. Berkley. 2010. Sublethal toxicant effects with dynamic energy budget theory: Model formulation. Ecotoxicology 19:38-47.

Navarro, E., A. Baun, R. Behra, N.B. Hartmann, J. Filser, A.J. Miao, A. Quigg, P.H. Santschi, and L. Sigg. 2008. Environmental behavior and ecotoxicity of engineered nanoparticles to algae, plants, and fungi. Ecotoxicology 17:372-386.

Neal, A.L. 2008. What can be inferred from bacterium-nanoparticle interactions about the potential consequences of environmental exposure to nanoparticles? Ecotoxicology 17:362-371.

Nelli, P., L.E. Depero, M. Ferroni, S. Groppelli, V. Guidi, F. Ronconi, L. Sangaletti, and G. Sberveglieri. 1996. Sub-ppm $\mathrm{NO}_{2}$ sensors based on nanosized thin films of titanium-tungsten oxides. Sens. Actuators B Chem. 31:89-92.

Nisbet, R.M., E.B. Muller, K. Lika, and S.A.L.M. Kooijman. 2000. From molecules to ecosystems through dynamic energy budget models. J. Anim. Ecol. 69:913-926.

Ogilvie-Robichaud, C., A.E. Uyar, M.R. Darby, L.G. Zucker, and M.R. Wiesner. 2009. Estimates of upper bounds and trends in nano- $\mathrm{TiO}_{2}$ production as a basis for exposure assessment. Environ. Sci. Technol. 43:4227-4233.

Osenberg, C.W., O. Sarnelle, and S.D. Cooper. 1997. Effect size in ecological experiments: The application of biological models in meta-analysis. Am. Nat. 150:798-812.

Owen, R., and R. Handy. 2007. Formulating the problems for environmental risk assessment of nanomaterials. Environ. Sci. Technol. 41:5582-5588.

Paleologou, A., H. Marakas, N.P. Xekoukoulotakis, A. Moya, Y. Vergara, N. Kalogerakis, P. Gikas, and D. Mantzavinos. 2007. Disinfection of water and wastewater by $\mathrm{TiO}_{2}$ photocatalysis, sonolysis and UV-C irradiation. Catal. Today 129:136-142.

Park, Y., K.Y. Dong, J. Lee, J. Choi, G.N. Bae, and B.K. Ju. 2009. Development of an ozone gas sensor using single-walled carbon nanotubes. Sens. Actuators B Chem. 140:407-411.

Phenrat, T., N. Saleh, K. Sirk, R.D. Tilton, and G.V. Lowry. 2007. Aggregation and sedimentation of aqueous nanoscale zerovalent iron dispersions. Environ. Sci. Technol. 41:284-290.
Plata, D.L., P.M. Gschwend, and C.M. Reddy. 2008. Industrially synthesized single-walled carbon nanotubes: Compositional data for users, environmental risk assessments, and source apportionment. Nanotechnology 19:185706.

Poland, C.A., R. Duffin, I. Kinloch, A. Maynard, W.A.H. Wallace, A. Seaton, V. Stone, S. Brown, W. MacNee, and K. Donaldson. 2009. Carbon nanotubes introduced into the abdominal cavity of mice show asbestoslike pathogenicity in a pilot study. Nat. Nanotechnol. 3:423-428.

Powell, M.C., M.P.A. Griffin, and S. Tai. 2008. Bottom up risk regulation? How nanotechnology risk knowledge gaps challenge federal and state environmental agencies. Environ. Manage. 42:426-443.

Project on Emerging Nanotechnologies. 2009. Consumer products inventory. Available at http://www.nanotechproject.org/inventories/consumer/ (verified 8 Sept. 2010).

Prospero, J.M. 1999. Long-range transport of mineral dust in the global atmosphere: Impact of African dust on the environment of the southeastern United States. Proc. Natl. Acad. Sci. USA 96:3396-3403.

Rattner, B.A. 2009. History of wildlife toxicology. Ecotoxicology 18:773-783.

Robichaud, C.O., D. Tanzil, U. Weilenmann, and M.R. Wiesner. 2005. Relative risk analysis of several manufactured nanomaterials: An insurance industry context. Environ. Sci. Technol. 39:8985-8994.

Rowland, F.S. 1991. Stratospheric ozone in the 21st-century: The chlorofluorocarbon problem. Environ. Sci. Technol. 25:622-628.

Sass, J., T. Musu, K. Burns, and I. Illuminato. 2008. Nanomaterials: Brief review of policy frameworks in the US and Europe and recommendations from an occupational and environmental perspective. Eur. J. Oncol. 13:211-218.

Sharma, V.K., R.A. Yngard, and Y. Lin. 2009. Silver nanoparticles: Green synthesis and their antimicrobial activities. Adv. Colloid Interface Sci. 145:83-96.

Simonson, R.W. 1995. Airborne dust and its significance to soils. Geoderma 65:1-43.

SmallTimes. 2005. Oxonica's deal with bus fleet puts company on right road. SmallTimes. Feb 7. Available at http://www.electroiq.com/index/ display/nanotech-article-display/269859/articles/small-times/environment/2005/02/oxonicas-deal-with-bus-fleet-puts-company-on-rightroad.html (verified 8 Sept. 2010).

Theng, B.K.G., and G. Yuan. 2008. Nanoparticles in the soil environment. Elements (Chantilly, VA, U. S.) 4:395-400.

Thill, A., O. Zeyons, F. Chauvat, G. Huberd, and O. Spalla. 2009. Physicochemical and biological interactions between manufactured nanoparticles and environmental bacteria. Geochim. Cosmochim. Acta 73:A1326-A1326.

Thill, A., O. Zeyons, O. Spalla, F. Chauvat, J. Rose, M. Auffan, and A.M. Flank. 2006. Cytotoxicity of $\mathrm{CeO}_{2}$ nanoparticles for Escherichia coli: Physico-chemical insight of the cytotoxicity mechanism. Environ. Sci. Technol. 40:6151-6156.

Toal, S.J., D. Magde, and W.C. Trogler. 2005. Luminescent oligo(tetraphenyl) silole nanoparticles as chemical sensors for aqueous TNT. Chem. Commun. (Camb.) 43:5465-5467.

Tong, Z.H., M. Bischoff, L. Nies, B. Applegate, and R.F. Turco. 2007. Impact of fullerene (C-60) on a soil microbial community. Environ. Sci. Technol. 41:2985-2991.

Tuljapurkar, S., and H. Caswell. 1997. Structured population models in marine, terrestrial, and freshwater systems. Chapman \& Hall, New York.

USNTC (U.S. National Science and Technology Council). 2004. The National Nanotechnology Initiative: Strategic plan. Available at http:// www.nano.gov/NNI_Strategic_Plan_2004.pdf (verified 4 Aug. 2010). Nanoscale Science, Engineering, and Technology Subcommittee, Nat. Technol. Coord. Office, Arlington, VA.

Whiteside, M.D., K.K. Treseder, and P.R. Atsatt. 2009. The brighter side of soils: Quantum dots track organic nitrogen through fungi and plants. Ecology 90:100-108.

Wiesner, M.R., G.V. Lowry, K.L. Jones, M.F. Hochella, R.T. Di Giulio, E. Casman, and E.S. Bernhardt. 2009. Decreasing uncertainties in assessing environmental exposure, risk, and ecological implications of nanomaterials. Environ. Sci. Technol. 43:6458-6462.

Yantasee, W., C.L. Warner, T. Sangvanich, R.S. Addleman, T.G. Carter, R.J. Wiacek, G.E. Fryxell, C. Timchalk, and M.G. Warner. 2007. Removal of heavy metals from aqueous systems with thiol functionalized superparamagnetic nanoparticles. Environ. Sci. Technol. 41:5114-5119.

Zhang, X.Z., H.W. Sun, Z.Y. Zhang, Q. Niu, Y.S. Chen, and J.C. Crittenden. 2007. Enhanced bioaccumulation of cadmium in carp in the presence of titanium dioxide nanoparticles. Chemosphere 67:160-166. 